\title{
Hybrid and Pureline Hard Winter Wheat Yield and Stability
}

\author{
John E. Koemel, Jr., Arron C. Guenzi,* Brett F. Carver, Mark E. Payton, George H. Morgan, and Edward L. Smith
}

\begin{abstract}
Pureline wheat (Triticum aestivum $\mathbf{L}$.) cultivars continue to dominate production fields in the southern Great Plains despite numerous attempts to introduce hybrids during the past $28 \mathrm{yr}$. The objective of this study was to analyze yield trends and yield stability in both hybrid and pureline entries in the Oklahoma Variety-Hybrid Performance Nursery (VHPN). Grain yield data from 1975 to 1995 from four locations were selected and analyzed by relative yield indices. Regression equations across time were calculated for both hybrids and purelines relative to the mean performance of long-term check cultivars. Both hybrids and purelines evidenced yield improvement, with the yield of hybrids, in general, increasing at a greater rate than that of purelines. Predicted values in the last year tested indicated a $\mathbf{1 0 . 9} \%$ advantage of hybrids over purelines. Stability parameters were compared by regressing hybrid and pureline yields on an environmental index based on location mean yields for checks. Regression coefficients for hybrids and purelines were not significantly different from one, nor from each other. Confidence intervals for hybrid and pureline performance generally overlapped throughout the observed yield ranges, indicating no divergence in predicted grain yield as environmental yield potential increased. No significant differences in stability between hybrids and purelines were found by comparing variances represented by the pooled deviations for each cultivar type. Hybrid wheat offers an opportunity for increased grain yield in the southern Great Plains of the USA, but without a stability advantage over pureline cultivars.
\end{abstract}

G RAIN YIELD POTENTIAL and stability in differing environments are important factors in establishing profitable wheat production systems. Advantages of hybrids over purelines have been suggested. However, only a very small hectarage has been devoted to hybrid wheat production since the first hybrid was commercially released $30 \mathrm{yr}$ ago (Edwards, 2001). Continuing inquiry is made regarding increased production of hybrid wheat when considering additional grain yield and stability that hybrid entries may have over their pureline counterparts.

Various procedures have been employed to estimate genetic gain in wheat improvement. Estimation of genetic gain for cultivars of different eras can be made by growing all in a common nursery and evaluating grain yield against year of release (Cox et al., 1988). For data taken in performance nurseries across years, a typical approach has been to analyze performance by evaluating yield through multiple-year moving averages and as

J.E. Koemel, Jr., A.C. Guenzi, B.F. Carver, G.H. Morgan, and E.L. Smith, Dep. of Plant and Soil Sci., Oklahoma State Univ., Stillwater, OK 74078-6028; M.E. Payton, Dep. of Statistics, Oklahoma State Univ., OK 74078. A contribution of the Oklahoma Agric. Exp. Stn. Part of a dissertation submitted by J.E. Koemel, Jr. in partial fulfillment of the Ph.D. degree requirements at Oklahoma State Univ. Received 29 May 2003. *Corresponding author (acg@okstate.edu).

Published in Crop Sci. 44:107-113 (2004).

(c) Crop Science Society of America

677 S. Segoe Rd., Madison, WI 53711 USA a percentage change from the yield of a long-term check (Schmidt and Worrall, 1983; Schmidt, 1984), or the use of moving means and least squares smoothing (Clarke et al., 1994). Relative yield is another method for analyzing grain yield performance and requires each entry in the nursery to be given a performance index based on its yield relative to the mean yield of all entries in the nursery (Yau and Hamblin, 1994). The use of relative yield as a measure of performance against all entries has several advantages, including (i) conversion of simple entry variance across sites to a practical, agronomic stability measure, (ii) the giving of equal weight to each site when calculating means across sites, and (iii) ease in comparing large numbers of entries tested in different experiments at the same site (Yau and Hamblin, 1994). However, the use of a relative yield index would not account for improvement across multiple years if a nursery index is used and the entries used to calculate the nursery index are not constant. This study used relative yield indices calculated from the mean yield of longterm check cultivars.

Of importance to an agronomic enterprise is the stability of yield of a cultivar across a range of production environments. The cultivar must have the genetic potential for superior performance under ideal growing conditions, and yet must also produce acceptable yields under less favorable environments. It has long been suggested that heterozygous and heterogeneous populations offer the best opportunity to produce cultivars that show small cultivar type $\times$ environment (GE) interactions (Eberhart and Russell, 1966). It has further been suggested that wheat hybrids and purelines appear to differ in their responsiveness to improving production conditions in the Great Plains of the USA (Guenzi et al., 1985). Carver et al. (1987) confirmed the disparity in responsiveness and found that the yield advantage of hybrids over semidwarf purelines decreased from $7.4 \%$ in the most productive environment to $5.0 \%$ in the least productive environments. A $10.8 \%$ yield advantage was calculated for hybrids over purelines in the preliminary performance nursery from the Agripro Standard Variety Trial, and a $13.5 \%$ average hybrid yield advantage was observed in the advanced trials (Bruns and Peterson, 1998). Evaluations of yield and stability suggest that hybrids show significantly higher mean yields and that the yield advantage generally increases with increasing environmental yield potential (Peterson et al., 1997). Peterson et al. (1997) also found that deviations from regressions for both the hybrids and the purelines were of similar magnitude, suggesting no evidence that hybrids provided an additional component of yield stability over purelines. Jordaan et al. (1999) found similar responses when comparing hybrids and purelines in

Abbreviations: GE, cultivar type $\times$ environment; VHPN, Oklahoma Variety-Hybrid Performance Nursery. 
South Africa. Hybrids were higher yielding than purelines in all environments and the hybrid yield advantage increased as the environmental yield index increased.

The objective of this study was to compare long-term yield trends and stability in both hybrid and pureline entries in the VHPN. The analysis focused on differences in grain yield between pureline and hybrid entries and evaluating the stability of grain yield performance in different production environments during a 21-yr period. There were two hypotheses: (i) that improvements made in grain yields differ for purelines vs. hybrids; and (ii) that hybrids and purelines exhibit different levels of stability for grain yield as demonstrated by the regressions being different from a slope of one and different from each other, and with the variance associated with pureline entries being greater than the variance associated with hybrid entries.

\section{MATERIALS AND METHODS}

\section{Yield Data}

For 21 yr (1975-1995), yield data were recorded in unpublished annual reports for hard winter wheat hybrids and purelines entered in the VHPN at Oklahoma State University pursuant to statutory testing requirements. The VHPN was discontinued after 1995 and hybrids have not been commercially available since 1998. Six environments were used to test hybrid and pureline cultivars. Field stations near Stillwater, Lahoma, Woodward, Goodwell, and Altus, OK, were used. The Goodwell location included both irrigated and dryland experiments. The Goodwell dryland site would be representative of extreme water stress in most years. However, data from this site were excluded from this analysis since data were missing in more than half of the test years, and had a high coefficient of variation for the years in which they were available. Data from the Woodward location were also excluded since this location was discontinued in 1992.

A core set of data from the remaining four locations, Goodwell irrigated, Stillwater, Lahoma, and Altus, was used for these analyses. Data for all years were available for these analyses, except for three years $(1979,1991,1993)$ at the Altus location. The Goodwell irrigated site is representative of a favorable environment with highly productive soils and supplemental irrigation to allow entries to reach their genetic potential. The Altus location is representative of an unfavorable environment, typically with moderate drought and heat stress, primarily late in the growing season. The locations at Stillwater and Lahoma generally receive adequate moisture but are influenced strongly by biotic stresses, particularly fungal pathogens and insects.

Thirty to 40 entries were included each year in the VHPN. The test was comprised of an assortment of prominent hybrids and purelines, including both private and public sector releases, and two long-term check cultivars, Triumph 64 and TAM W-101. In any given year, the nursery entries represented the most advanced genetic materials commercially available in the region. For each year and location, the entries were grown in a randomized complete block design with four replications at each location. All locations were fertilized at levels consistent with good management in the area and were generally seeded at normal planting dates for the area, given proper soil moisture conditions and weather conditions. Plot size was 1.2 by $3.1 \mathrm{~m}$, consisting of either four or five rows. All plots were harvested with a Hege 125B combine harvester.
Harvest dates ranged from mid-June until early July. Data used for statistical analyses consisted of entry mean yields at each location.

\section{Genetic Gain Analysis}

All 21 yr of grain yield data were analyzed in evaluating improvement in hybrid and pureline wheat performance. No adjustments were made for conventional vs. semidwarf entries. Data for a particular entry were limited to the first $5 \mathrm{yr}$ from the year that it was first tested. The 5-yr limitation was to prevent bias to pureline yields, which were occasionally included for more than five consecutive years. Similarly, data from entries with a release date in 1971 or earlier were excluded from the analysis. In total, 122 purelines and 104 hybrid entries were included for analysis. On average, each pureline entry was included in the nursery for $2.6 \mathrm{yr}$, and each hybrid entry was included for $1.7 \mathrm{yr}$.

The grain yield performance of hybrids and purelines was analyzed across time by comparing the grain yield of each relative to the mean of the long-term check cultivars, given that mean grain yield of the long-term checks remained constant across time. Effects of cultivar type (hybrid or pureline), environment, and GE interactions were analyzed. A linear model was utilized. Year and location effects were assumed to be random and cultivar-type effects were assumed to be fixed in the statistical model. All trends in grain yield were analyzed by year, after noting large annual effects. Relative yield indices were calculated for both hybrids and purelines at each location by dividing the mean grain yield for each by the mean grain yield of TAM W-101 and Triumph 64 . Regression analysis (SAS Institute, 1996) was used to test the rate of gain of hybrids against purelines.

\section{Stability Analysis}

Yield stability was analyzed similar to that suggested by Eberhart and Russell (1966). Stability was defined as a function of slope and deviations from the regression of cultivar yield on an environmental index. First, the linear regression coefficients of the hybrids and purelines $\left(b_{\mathrm{H}}\right.$ and $b_{\mathrm{P}}$, respectively) were calculated by use of the mean yield of hybrids and purelines by location against an environment index based on the mean yield of TAM W-101 and Triumph 64 in that environment. Differences in the calculated slopes for hybrids and purelines were tested for significance from a slope of one, and from each other. Pooled deviations from the linear response, in terms of $\operatorname{SE}(b)$, were compared.

Each year of the VHPN was then analyzed separately with PROC MIXED (SAS Institute, 1996) to test the heterogeneity of slopes between hybrids and purelines, and among entries within these two cultivar type classes. Entries within cultivar type classes were considered random. Variance components of the random effects and interaction terms were estimated and tested for significance. The fixed effect (cultivar type) was analyzed by comparing the estimated mean grain yield and standard error by year. Genetic variance components of hybrids and purelines were also estimated for each year with PROC MIXED (SAS Institute, 1996). One-tailed $F$ tests were constructed to declare whether entry variances for purelines were greater than entry variances for hybrids.

\section{RESULTS AND DISCUSSION} Genetic Gain Analysis

A large proportion of the variability for grain yield of both hybrids and purelines was due to the effects 
Table 1. Regression analyses for grain yield of hybrid and pureline cultivars against time for entries grown in the Oklahoma Variety-Hybrid Performance Nursery during 1975 to 1995.

\begin{tabular}{|c|c|c|c|c|}
\hline Location & Mean & Intercept & Slope $†$ & $r^{2}$ \\
\hline & $-\mathbf{N}$ & $\mathbf{h a}^{-1}$ & $\mathrm{Mg} \mathrm{ha}^{-1} \mathrm{yr}^{-}$ & \\
\hline \multicolumn{5}{|l|}{ Goodwell irrigated } \\
\hline Hybrids & 4.83 & 3.32 & 0.018 & 0.010 \\
\hline Purelines & 4.77 & 5.22 & -0.005 & 0.001 \\
\hline Long-term checks & 4.52 & 6.76 & -0.026 & 0.029 \\
\hline \multicolumn{5}{|l|}{ Stillwater } \\
\hline Hybrids & 3.13 & 2.05 & 0.013 & 0.010 \\
\hline Purelines & 2.88 & 2.93 & -0.001 & $<\mathbf{0 . 0 0 1}$ \\
\hline Long-term checks & 2.70 & 4.90 & -0.026 & 0.051 \\
\hline \multicolumn{5}{|l|}{ Lahoma } \\
\hline Hybrids & 3.18 & 1.12 & 0.024 & 0.029 \\
\hline Purelines & 3.03 & 2.72 & 0.004 & 0.001 \\
\hline Long-term checks & 2.94 & 5.49 & $-\mathbf{0 . 0 3 0}$ & 0.048 \\
\hline \multicolumn{5}{|l|}{ Altus } \\
\hline Hybrids & 2.90 & 1.90 & 0.012 & 0.007 \\
\hline Purelines & 2.74 & 3.04 & -0.004 & 0.001 \\
\hline Long-term checks & 2.67 & 2.99 & -0.004 & 0.001 \\
\hline \multicolumn{5}{|l|}{ Pooled } \\
\hline Hybrids & 3.53 & 1.95 & 0.019 & 0.009 \\
\hline Purelines & 3.38 & 3.34 & 0.000 & $<\mathbf{0 . 0 0 1}$ \\
\hline Long-term checks & 3.22 & 4.99 & -0.021 & 0.013 \\
\hline
\end{tabular}

$\dagger$ Regression year is the number of years after 1900 .

of location and years but without a significant year $x$ location interaction. The regression components by location for both hybrids and purelines are presented in Table 1.

The mean yields of the long-term check cultivars were used to estimate relative yield. The check means exhibited no significant linear change across the 21-yr period (Fig. 1). If a trend in the long-term checks exists, the regression analysis suggests a slight decline in yield of $0.0208 \mathrm{Mg} \mathrm{ha}^{-1} \mathrm{yr}^{-1}\left(0.31 \mathrm{bu} \mathrm{acre}^{-1} \mathrm{yr}^{-1}\right)$. A true decline in check mean across time would generate an upward

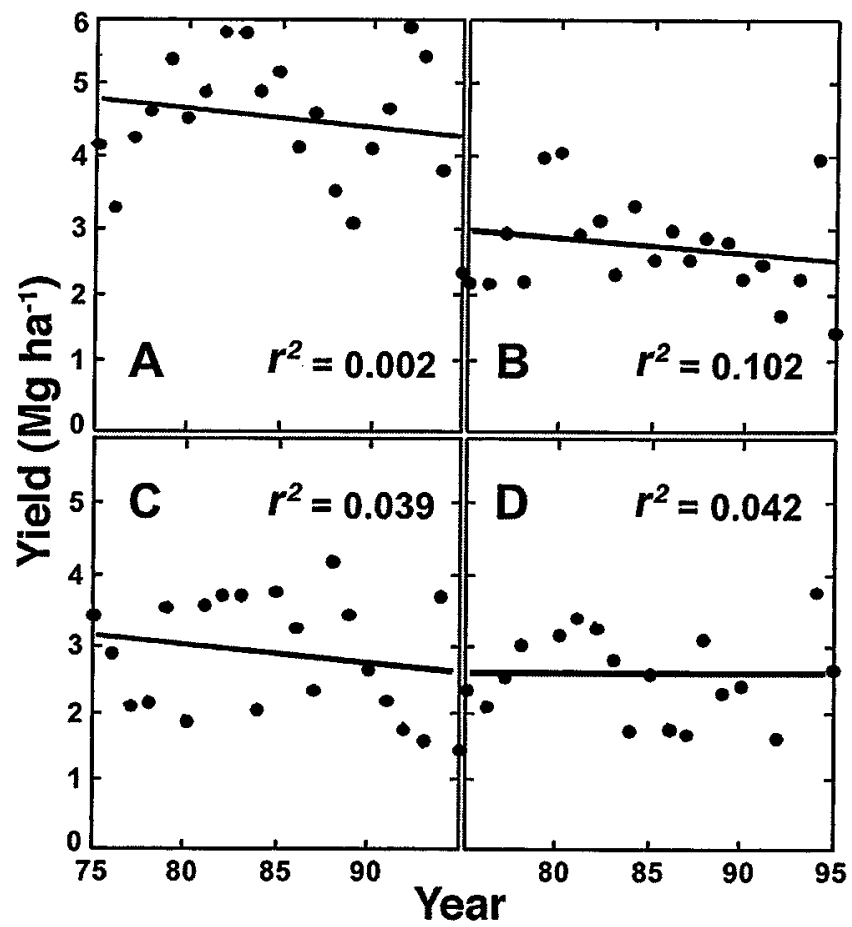

Fig. 1. Mean grain yield of long-term check purelines ('TAM W-101' and 'Triumph 64') by year and location with linear regressions plotted for (A) Goodwell irrigated, (B) Stillwater, (C) Lahoma, and (D) Altus, OK.
Table 2. Regression analyses for relative grain yield indices of hybrid and pureline cultivars against time for entries grown in the Oklahoma Variety-Hybrid Performance Nursery during 1975 to 1995.

\begin{tabular}{|c|c|c|c|c|}
\hline Location & Mean & Intercept & Slope $\dagger$ & $r^{2}$ \\
\hline \multicolumn{5}{|c|}{ Goodwell irrigated } \\
\hline Hybrids & 1.073 & 0.155 & $0.011 * *$ & 0.329 \\
\hline Purelines & 1.058 & 0.668 & 0.005 & 0.131 \\
\hline \multicolumn{5}{|l|}{ Stillwater } \\
\hline Hybrids & 1.169 & -0.548 & $0.020 * * *$ & 0.560 \\
\hline Purelines & 1.082 & -0.057 & $0.013 * *$ & 0.407 \\
\hline \multicolumn{5}{|l|}{ Lahoma } \\
\hline Hybrids & 1.110 & -0.896 & $0.024 * * *$ & 0.541 \\
\hline Purelines & 1.054 & -0.221 & $0.015 * * *$ & 0.470 \\
\hline \multicolumn{5}{|l|}{ Altus } \\
\hline Hybrids & 1.075 & 0.642 & 0.005 & 0.087 \\
\hline Purelines & 1.021 & 1.123 & -0.001 & 0.005 \\
\hline \multicolumn{5}{|l|}{ Pooled } \\
\hline Hybrids & 1.112 & -0.206 & $0.015 * * *$ & 0.364 \\
\hline Purelines & 1.054 & $\mathbf{0 . 3 3 7}$ & $\mathbf{0 . 0 0 8}^{* * *}$ & 0.201 \\
\hline
\end{tabular}

** Significantly different from a slope of zero at the 0.01 level.

*** Significantly different from a slope of zero at the 0.001 level.

$\dagger$ Regression year is the number of years after 1900 .

bias in the estimation of genetic gain of hybrids and purelines. Such a decline would also not readily be explained by genetic causes. However, there could be environmental reasons, such as a check cultivar succumbing to new virulent strains of pathogens, a decline in native fertility associated with the loss of organic matter from continuously tilled plots, or effects caused by changes in agronomic practices. Note, however, that if genetic gain is calculated by use of a pureline or nursery index, then performance would be evaluated against a moving standard, possibly with abrupt fluctuations with periodic releases of superior purelines or as new hybrids were developed. The use of a pureline or nursery environmental index, while eliminating much of the year-to-year environmental effects, would fail to compensate for

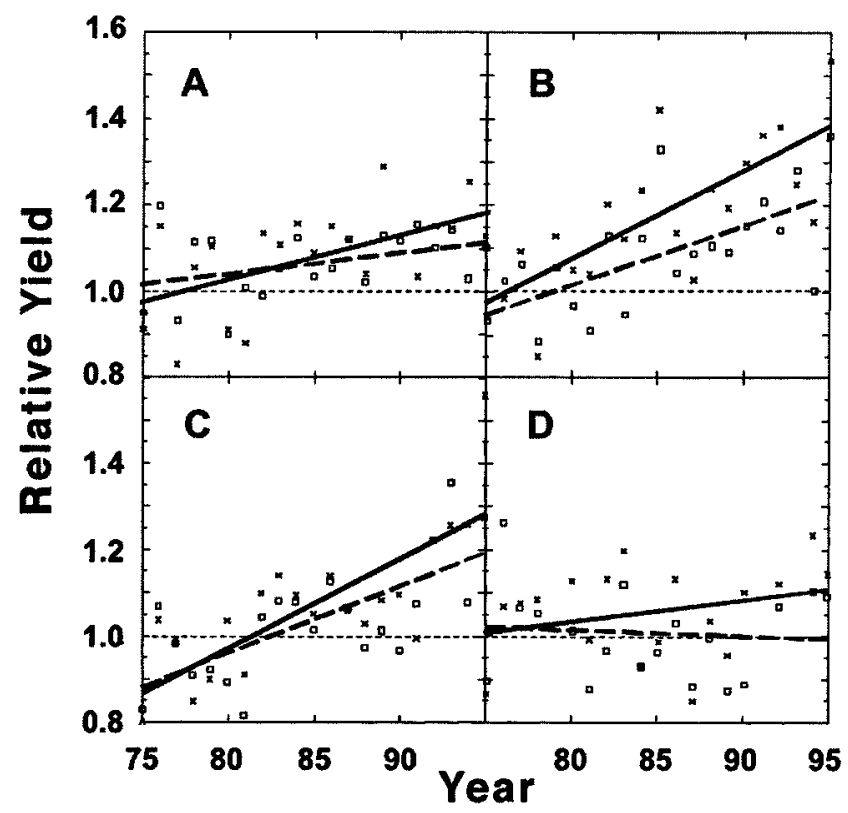

Fig. 2. Linear regressions for relative yield of hybrids (solid line with $\times$ symbols) and purelines (dashed line with square symbols) by year for (A) Goodwell irrigated, (B) Stillwater, (C) Lahoma, and (D) Altus, OK. The check mean reference (dotted line) is equal to 1.0 by definition. 
Table 3. Summary of improvement for hybrids and purelines by location from predicted values of relative yield for entries grown in the Oklahoma Variety-Hybrid Performance Nursery during 1975 to 1995.

\begin{tabular}{|c|c|c|c|c|c|}
\hline \multirow[b]{2}{*}{ Location } & \multicolumn{2}{|c|}{ Predicted value } & \multirow{2}{*}{$\begin{array}{c}\text { Annual } \\
\text { progress }\end{array}$} & \multicolumn{2}{|c|}{ Advantage over } \\
\hline & 1975 & 1995 & & Pureline & Check mear \\
\hline \multirow{2}{*}{\multicolumn{6}{|c|}{ Goodwell irrigated }} \\
\hline & & & & & \\
\hline Hybrids & 0.966 & 1.183 & 1.07 & 7.14 & 18.3 \\
\hline Purelines & 1.012 & 1.104 & $\mathbf{0 . 4 3}$ & - & 10.4 \\
\hline \multicolumn{6}{|l|}{ Stillwater } \\
\hline Hybrids & 0.966 & 1.370 & 1.99 & 12.94 & 37.0 \\
\hline Purelines & 0.946 & 1.213 & 1.35 & - & 21.3 \\
\hline \multicolumn{6}{|l|}{ Lahoma } \\
\hline Hybrids & 0.871 & 1.342 & 2.58 & 11.83 & 34.2 \\
\hline Purelines & 0.901 & 1.200 & 1.58 & - & 20.0 \\
\hline \multicolumn{6}{|l|}{ Altus } \\
\hline Hybrids & 1.024 & 1.126 & 0.47 & 11.55 & 12.6 \\
\hline Purelines & 1.033 & 1.009 & -0.11 & - & 0.9 \\
\hline \multicolumn{6}{|l|}{ Pooled } \\
\hline Hybrids & 0.954 & 1.263 & 1.54 & 10.88 & 26.3 \\
\hline Purelines & 0.970 & 1.139 & 0.83 & - & 13.9 \\
\hline
\end{tabular}

changes in entry performance across time due to continual improvement of nursery entries.

The regression components for a linear model by location when calculated with relative indices are presented in Table 2 and plotted in Fig. 2. In general, genetic gain was realized in both hybrid and pureline performance. However, when evaluated on a location basis, maximum annual improvement in hybrid performance occurred at the Lahoma and Stillwater locations; intermediate gain at the Goodwell irrigated location; and questionable gain if at all, particularly for pureline performance, at the Altus location.

The hybrid rates of improvement were significantly different from zero at all locations except for Altus. The pureline rates of improvement were significantly different from zero only at Stillwater and Lahoma (Table 2). In general, the rate of improvement for hybrid performance exceeded that for pureline performance.

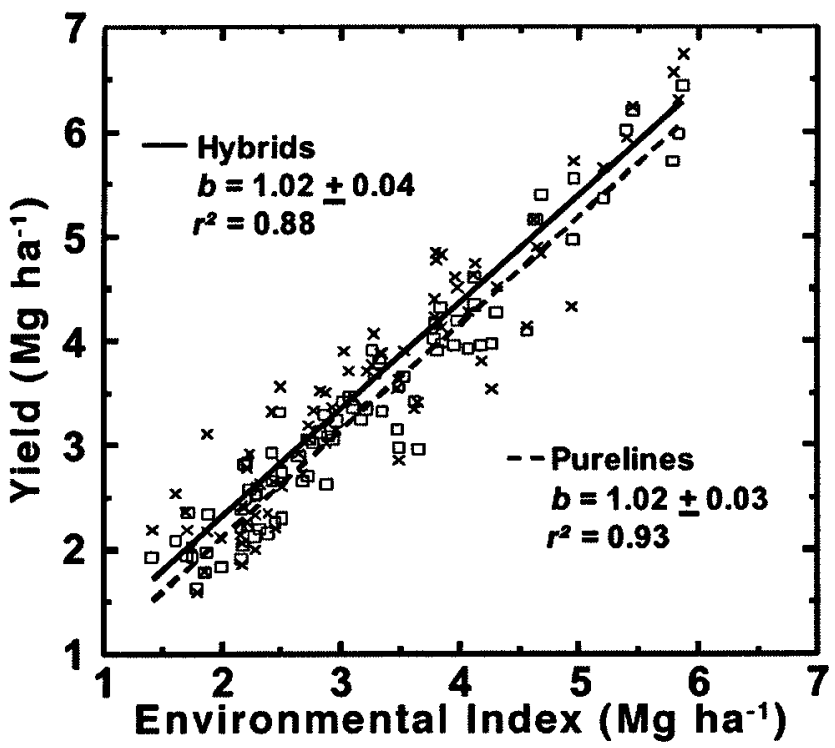

Fig. 3. Mean grain yield of hybrids (solid line with $\times$ symbols) and purelines (dashed line with square symbols) against a check environmental index.

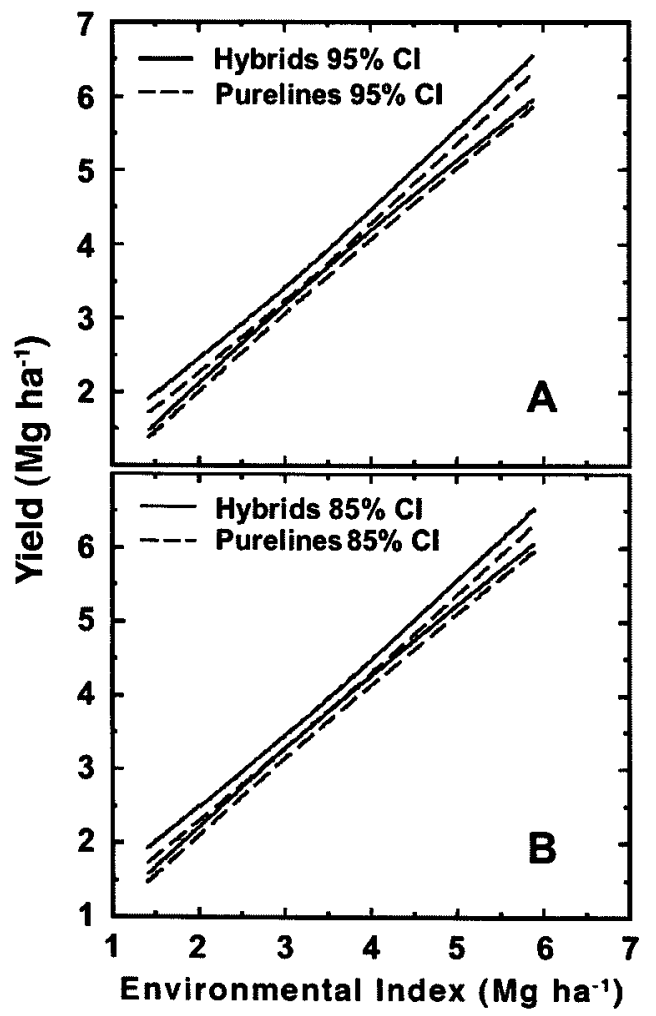

Fig. 4. Comparison of (A) $95 \%$ and (B) $85 \%$ confidence intervals (CI) of hybrids (solid lines) and purelines (dashed lines) to approximate a test of differences between the two populations at $\alpha=0.01$ and 0.05 , respectively.

Across locations, the rate of improvement for hybrids was $1.55 \%$ and for purelines was $0.84 \%$, indicating a significant difference between the two $(P=0.02)$. These rates of improvement were generally consistent with earlier reported estimates of genetic gain in pureline wheat breeding of $1 \%$ per year (Borojevic, 1986; Cox et al., 1988; Khalil et al., 2002). When data were considered on a per-location basis, the differences in rates of improvement were found not to be significant at any location based on the probabilities for heterogeneity of slopes (Goodwell irrigated, $P=0.172$; Stillwater, $P=$ 0.226; Lahoma, $P=0.171$; and Altus, $P=0.294$ ).

Rates of improvement based only on grain yield may require additional interpretation. Breeding efforts may contribute to factors whose improvement is not necessarily reflected in grain yield, such as improvement in grain quality. Some factors, such as continual emphasis on disease resistance, may be particularly evident in having a positive influence on yield at the Stillwater and Lahoma locations. The presumption of high environmental stress at the Altus location suggests that the more recent entries failed to improve grain yield over that of the long-term check cultivars. The same trend was found by Cox et al. (1988) for hard winter wheat purelines released from 1919 to 1987.

In the last year of testing (1995), the predicted values evidenced a $26.3 \%$ advantage for hybrids, and a $13.9 \%$ advantage for purelines, on average, over the long-term checks. Additionally, the predicted yield advantage of the hybrids over the purelines was on average $10.9 \%$ 
Table 4. Estimated variance components (VC) of random effects from regressions of hybrid and pureline grain yields on long-term checks environmental index for entries in the Oklahoma Variety-Hybrid Performance Nursery during 1975-1995.

\begin{tabular}{|c|c|c|c|c|c|c|c|c|c|c|c|c|c|c|}
\hline Source & df & $\mathbf{V C}$ & df & $\mathbf{V C}$ & df & $\mathbf{V C}$ & df & $\mathbf{V C}$ & df & $\mathbf{V C}$ & df & $\mathbf{V C}$ & df & $\mathbf{V C}$ \\
\hline & \multicolumn{2}{|c|}{$\underline{1975}$} & \multicolumn{2}{|r|}{1976} & \multicolumn{2}{|c|}{$\underline{1977}$} & \multicolumn{2}{|r|}{$\underline{1978}$} & \multicolumn{2}{|c|}{1979} & \multicolumn{2}{|r|}{$\underline{1980}$} & \multicolumn{2}{|r|}{1981} \\
\hline All Entries & & & & & & & & & & & & & & \\
\hline Environment-linear & 1 & 0.697 & 1 & 0.516 & 1 & 0.380 & 1 & 2.168 & 1 & 1.727 & 1 & 1.036 & 1 & 0.611 \\
\hline Cultivar type $\times$ Environment-linear & 1 & 0.000 & 1 & 0.004 & 1 & 0.023 & 1 & 0.001 & 1 & 0.015 & 1 & 0.000 & 1 & 0.117 \\
\hline Entry (cultivar type) & 20 & $\mathbf{0 . 0 3 6} *$ & 24 & $0.089 * *$ & 24 & $\mathbf{0 . 0 3 5} *$ & 24 & 0.015 & 23 & $0.043 \dagger$ & 19 & 0.034 & 21 & $0.133 *$ \\
\hline Entry (cultivar type) $\times$ Environment-linear & 20 & 0.000 & 24 & 0.000 & 24 & 0.000 & 24 & 0.000 & 23 & 0.000 & 19 & 0.000 & 21 & 0.000 \\
\hline Deviations & 44 & 0.057 & 52 & 0.105 & 52 & 0.100 & 52 & 0.107 & 25 & 0.114 & 42 & 0.151 & 46 & 0.313 \\
\hline \multicolumn{15}{|l|}{ Hybrids } \\
\hline Environment-linear & 1 & 0.626 & 1 & 0.536 & 1 & 0.285 & 1 & 2.012 & 1 & 2.218 & $\mathbf{1}$ & 0.982 & 1 & 0.268 \\
\hline Entry (hybrids) & 8 & $\mathbf{0 . 0 3 4}$ & 15 & $\mathbf{0 . 0 3 7 \dagger}$ & 9 & 0.028 & 5 & 0.000 & 7 & 0.023 & 4 & 0.026 & 5 & 0.000 \\
\hline Entry (hybrids) $\times$ Environment-linear & 8 & 0.000 & 15 & 0.000 & 9 & 0.000 & 5 & 0.000 & 7 & 0.000 & 4 & 0.000 & 5 & 0.000 \\
\hline Deviations & 18 & $\mathbf{0 . 0 4 7}$ & 32 & 0.078 & 20 & $\mathbf{0 . 0 8 7}$ & 12 & 0.133 & 8 & 0.095 & 10 & 0.045 & 12 & 0.214 \\
\hline \multicolumn{15}{|l|}{ Purelines } \\
\hline Environment-linear & $\mathbf{1}$ & 0.744 & 1 & 0.496 & $\mathbf{1}$ & 0.509 & 1 & 27.461 & 1 & 1.694 & 1 & 1.054 & 1 & 1.097 \\
\hline Entry (pureline) & 12 & $\mathbf{0 . 0 3 6} \dagger$ & 9 & $\mathbf{0 . 1 7 5} \dagger$ & 15 & 0.039 & 19 & 0.184 & 16 & 0.029 & 15 & 0.035 & 16 & $\mathbf{0 . 1 7 5} \dagger$ \\
\hline Entry (pureline) $\times$ Environment-linear & 12 & 0.000 & 9 & 0.000 & 15 & 0.000 & 19 & 0.057 & 16 & 0.000 & 15 & 0.000 & 16 & 0.000 \\
\hline \multirow[t]{2}{*}{ Deviations } & 26 & 0.066 & 20 & 0.148 & 32 & 0.107 & 40 & 2.757 & 17 & 0.047 & 32 & 0.183 & 34 & 0.344 \\
\hline & \multicolumn{2}{|c|}{ 1982 } & \multicolumn{2}{|r|}{$\underline{1983}$} & \multicolumn{2}{|c|}{$\underline{1984}$} & \multicolumn{2}{|r|}{$\underline{1985}$} & \multicolumn{2}{|c|}{1986} & \multicolumn{2}{|r|}{1987} & & $1988+$ \\
\hline All Entries & & & & & & & & & & & & & & \\
\hline Environment-linear & 1 & 1.471 & 1 & 2.494 & $\mathbf{1}$ & 2.970 & 1 & 1.446 & 1 & 1.087 & 1 & 2.274 & $\mathbf{1}$ & 0.258 \\
\hline Cultivar type $\times$ Environment-linear & 1 & 0.035 & 1 & 0.000 & 1 & 0.009 & 1 & 0.000 & 1 & 0.004 & 1 & 0.000 & 1 & 0.000 \\
\hline Entry (cultivar type) & 19 & $\mathbf{0 . 0 8 8} *$ & 19 & 0.029 & 22 & 0.004 & 30 & $\mathbf{0 . 1 3 3} * *$ & 23 & $0.062 *$ & 23 & 0.034* & 20 & $0.116 * *$ \\
\hline Entry (cultivar type) $\times$ Environment-linear & 19 & 0.000 & 19 & 0.000 & 22 & 0.000 & 30 & 0.000 & 23 & 0.000 & 23 & 0.000 & 20 & 0.000 \\
\hline Deviations & 42 & 0.091 & 42 & 0.149 & 48 & 0.066 & 64 & 0.106 & 50 & 0.077 & 50 & 0.074 & 44 & 0.092 \\
\hline Hybrids & & & & & & & & & & & & & & \\
\hline Environment-linear & 1 & 1.768 & 1 & 2.475 & 1 & 3.130 & 1 & 1.528 & 1 & 1.148 & 1 & 2.324 & 1 & 0.257 \\
\hline Entry (hybrids) & 13 & $\mathbf{0 . 0 5 8} \dagger$ & 16 & 0.027 & 14 & 0.008 & 17 & 0.119* & 8 & 0.054 & 8 & 0.026 & 5 & 0.011 \\
\hline Entry (hybrids) $\times$ Environment-linear & 13 & 0.000 & 16 & 0.000 & 14 & 0.000 & 17 & 0.000 & 8 & 0.000 & 8 & 0.000 & 5 & 0.000 \\
\hline Deviations & 28 & $\mathbf{0 . 0 7 3}$ & 34 & 0.175 & 30 & 0.063 & 36 & 0.072 & 18 & 0.061 & 18 & 0.054 & 12 & 0.058 \\
\hline Purelines & & & & & & & & & & & & & & \\
\hline Environmen & $\mathbf{1}$ & 1.195 & 1 & 2.562 & $\mathbf{1}$ & 2.794 & $\mathbf{1}$ & 1.336 & 1 & 1.0 & 1 & 2.243 & $\mathbf{1}$ & 0.259 \\
\hline Entry (purelines) & 6 & $\mathbf{0 . 1 5 3}$ & 3 & 0.028 & 8 & 0.000 & 13 & 0.151* & 15 & $0.067 *$ & 15 & $\mathbf{0 . 0 3 8} \dagger$ & 15 & $0.151 *$ \\
\hline Entry (purelines) $\times$ Environment-linear & 6 & 0.000 & 3 & 0.000 & 8 & 0.000 & 13 & 0.000 & 15 & 0.000 & 15 & 0.000 & 15 & 0.000 \\
\hline Deviations & 14 & $\mathbf{0 . 1 3 0}$ & 8 & 0.050 & 18 & 0.068 & 28 & 0.154 & 32 & 0.086 & 32 & 0.089 & 32 & 0.104 \\
\hline & & 1989 & & $\underline{1990}$ & & 991 & & $1992 \div$ & & 1993 & & 1994 & & 1995 \\
\hline All Entries & & & & & & & & & & & & & & \\
\hline Envi & 1 & 0.447 & 1 & 0.984 & 1 & 1.942 & 1 & 4.773 & 1 & 4.464 & 1 & 0.026 & 1 & 0.210 \\
\hline Cultivar type $\times$ Environment-linear & 1 & 0.000 & 1 & 0.007 & 1 & 0.100 & 1 & 0.016 & 1 & 0.000 & 1 & 0.002 & 1 & 0.003 \\
\hline Entry (cultivar type) & 28 & $\mathbf{0 . 0 3 0} \uparrow$ & 25 & $0.082 *$ & 23 & 0.000 & 22 & $0.072 *$ & 21 & $\mathbf{0 . 1 3 2} *$ & 18 & $0.111 * *$ & 20 & $0.087 *$ \\
\hline Entry (cultivar type) $\times$ Environment-linear & 28 & 0.000 & 25 & 0.000 & 23 & 0.000 & 22 & 0.000 & 21 & 0.000 & 18 & 0.000 & 20 & 0.000 \\
\hline Deviations & 60 & 0.115 & 54 & 0.138 & 25 & 0.143 & 48 & 0.165 & 23 & $\mathbf{0 . 1 0 8}$ & 40 & 0.064 & 44 & 0.116 \\
\hline Hybrids & & & & & & & & & & & & & & \\
\hline Environment-linear & 1 & 0.524 & 1 & 0.702 & 1 & 1.548 & 1 & 4.701 & 1 & 4.782 & 1 & 0.000 & 1 & 0.158 \\
\hline Entry (hybrids) & 6 & 0.000 & 4 & 0.000 & 4 & 0.000 & 3 & 0.003 & 2 & 0.000 & 1 & 0.089 & 6 & 0.043 \\
\hline Entry (hybrids) $\times$ Environment-linear & 6 & 0.000 & 4 & 0.000 & 4 & 0.000 & 3 & 0.000 & 2 & 0.000 & 1 & 0.000 & 6 & 0.000 \\
\hline Deviations & 14 & 0.057 & 10 & 0.139 & 5 & 0.210 & 8 & 0.088 & 3 & 0.056 & 4 & 0.129 & 14 & 0.090 \\
\hline Purel & & & & & & & & & & & & & & \\
\hline Environment-linear & 1 & 0.425 & 1 & 1.099 & $\mathbf{1}$ & 2.441 & 1 & 4.833 & $\mathbf{1}$ & 4.415 & 1 & 0.033 & 1 & 0.244 \\
\hline Entry (purelines) & 22 & $0.038 \dagger$ & 21 & 0.104* & 19 & 0.000 & 19 & $0.083 *$ & 19 & $0.147 *$ & 17 & $0.113 * *$ & 14 & $0.105^{*}$ \\
\hline Entry (purelines) $\times$ Environment-linear & 22 & 0.000 & 21 & 0.000 & 19 & 0.000 & 19 & 0.000 & 19 & 0.000 & 17 & 0.000 & 14 & 0.000 \\
\hline Deviations & 46 & 0.132 & 44 & 0.131 & 20 & 0.129 & 40 & 0.177 & 20 & 0.115 & 36 & 0.056 & 30 & 0.128 \\
\hline
\end{tabular}

* Variance components significant at the 0.05 level.

** Variance components significant at the 0.01 level.

$\dagger$ Variance components significant at the 0.10 level.

† By year, variance component of purelines significantly greater than variance component of hybrids at the 0.10 level.

(Table 3). This relative advantage of hybrids over purelines is consistent with the $10.8 \%$ advantage reported in preliminary trials and the $13.5 \%$ advantage reported in advanced trials by Bruns and Peterson (1998). A heterotic yield advantage of $20 \%$ was suggested (Johnson and Lucken, 1986) as the minimal advantage required to economically justify the production of hybrid wheat over pureline wheat when considering the additional costs associated with production, particularly seed costs. Other considerations may also be relevant, such as the use of hybrid wheat in the deployment of transgenes. These results suggest that the heterotic advantage of hybrids over purelines is approaching this range for each of the locations analyzed.

The largest advantage of grain yield of hybrids over purelines did not occur at the Goodwell irrigated loca- tion $(7.14 \%)$ despite suggestions that maximum benefit of hybrids over purelines is realized in high-yield environments. On the other hand, considerable literature has shown that an inherent advantage of hybrids should be a superior buffering to the environment. Hybrids excelled $(>10 \%)$ over purelines in the three remaining lower-yielding environments (Table 3 ).

\section{Stability Analysis}

In analyzing yield stability, annual mean yield of hybrids and purelines by location were plotted against an environmental index (Fig. 3). The environmental index was determined from the annual mean yield of the longterm check cultivars for each location. By definition, the regression of the mean yield of the long-term checks 
in the stability analysis would have a slope of one $(b=1.0)$.

The regression equations for hybrids and purelines were similar when calculated with the annual mean yields by location of the hybrids and purelines against the corresponding mean check yield. The hybrid stability slope $\left(b_{\mathrm{H}}\right)$ was identical to that for the purelines $\left(b_{\mathrm{P}}\right)$ $\left(P\left[b_{\mathrm{H}}=b_{\mathrm{P}}\right]=1.02\right)($ Fig. 3$)$. In both cases, the slopes were not significantly different from one. The intercept for hybrids was $0.15 \mathrm{Mg} \mathrm{ha}^{-1}$ greater than that for the purelines. For comparison purposes, when the same analysis was performed utilizing the pureline mean as the environmental index rather than the check mean, little adjustment occurred and the $b_{\mathrm{H}}$ was approximately 0.997 , with the $b_{\mathrm{P}}$ being one by definition.

Deviations from regression did not differ between hybrids and purelines based on a comparison of the standard errors associated with the regressions (Fig. 3). This is similar to the report by Peterson et al. (1997), and suggests no stability advantage of hybrids across differing environments.

When comparing differences between hybrids and purelines for predicted grain yield in a specific environment, consideration was given to variability associated with both regressions. The confidence bands for both hybrids and purelines were interpreted simultaneously to test differences in predicted yield at a given environmental index. Significant differences can be declared if the confidence bands fail to overlap. Since both confidence bands require a confidence limit to be set, these limits were set to assure that the desired error rate for the test was attained. Comparison of two $95 \%$ confidence intervals performed on the same population will overlap approximately $1 \%$ of the time (Payton et al., 2000). Therefore, if intervals are to be used to judge significance, care must be taken to use the appropriate

Table 5. Means of cultivar types for entries in the Oklahoma Variety-Hybrid Performance Nursery during 1975 to 1995.

\begin{tabular}{|c|c|c|c|c|}
\hline \multirow[b]{2}{*}{ Year } & \multicolumn{2}{|c|}{ Hybrids } & \multicolumn{2}{|c|}{ Purelines } \\
\hline & Mean & SE & Mean & SE \\
\hline & & 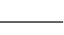 & & \\
\hline 1975 & 2.71 & 0.42 & 2.80 & 0.42 \\
\hline 1976 & 2.84 & 0.37 & 3.04 & 0.38 \\
\hline 1977 & 2.96 & 0.33 & 3.04 & 0.32 \\
\hline 1978 & 3.03 & 0.74 & 3.13 & 0.74 \\
\hline 1979 & 4.58 & 0.77 & 4.54 & 0.76 \\
\hline $1980 \dagger$ & 3.54 & 0.52 & 3.29 & 0.51 \\
\hline 1981 & 3.56 & 0.47 & 3.41 & 0.44 \\
\hline $1982 \dagger$ & 4.58 & 0.62 & 4.13 & 0.63 \\
\hline $1983 \dagger$ & 4.19 & 0.79 & 3.90 & 0.80 \\
\hline 1984 & 3.48 & 0.86 & 3.34 & 0.86 \\
\hline 1985 & 4.00 & 0.61 & 3.82 & 0.61 \\
\hline 1986 & 3.52 & 0.53 & 3.29 & $\mathbf{0 . 5 3}$ \\
\hline 1987 & 2.98 & 0.76 & 3.04 & 0.76 \\
\hline 1988 & 3.74 & 0.30 & 3.54 & 0.27 \\
\hline $1989 * *$ & 3.35 & 0.35 & 3.05 & 0.34 \\
\hline 1990 & 3.34 & 0.52 & 3.04 & 0.50 \\
\hline 1991 & 3.48 & 0.83 & 3.60 & 0.83 \\
\hline $1992 \dagger$ & 3.54 & 1.11 & 3.15 & 1.10 \\
\hline 1993 & 3.72 & 1.24 & 3.79 & 1.22 \\
\hline 1994* & 4.74 & 0.26 & 4.08 & 0.12 \\
\hline 1995 & 2.61 & 0.26 & 2.39 & 0.25 \\
\hline
\end{tabular}

* Means of hybrids and purelines significantly different at the 0.05 level. ** Means of hybrids and purelines significantly different at the 0.01 level. $\dagger$ Means of hybrids and purelines significantly different at the 0.10 level. confidence level to best approximate the desired error rate. An $\alpha=0.05$ test is approximated by plotting and comparing $85 \%$ confidence bands, and a more conservative $\alpha=0.01$ test is approximated by the $95 \%$ confidence bands (Payton et al., 2000). In plotting these bands and making tests between two populations, there was no divergence in performance between hybrids and purelines when comparing the $95 \%$ confidence bands (Fig. 4A). There was also no divergence in performance between hybrids and purelines when comparing the $85 \%$ confidence bands, except for a few intermediate production environments (Fig. 4B). The overlapping confidence intervals show that there was no advantage for hybrids in high yield environments or in low yield environments over purelines. Stated conversely, there was no disadvantage for hybrids in any production environment.

The variance components estimated for the random effects are presented by year in Table 4, with environment estimating the effect of the four different locations, and entry estimating the genetic variance within a cultivar type class. The mean grain yields for the fixed effects are presented by year in Table 5. There was a significant entry effect declared at $\alpha=0.10$ in a majority (13 of 21) of the test years for purelines, but in only three years for the hybrids. No significant differences in stability between hybrids and purelines were declared by comparing variances represented by the pooled deviations for each cultivar type. However, significant differences were declared at $\alpha=0.10$ between the estimated variance components of hybrids and purelines in 1976, 1982, 1988, and 1992. Pureline variance components were equal to or greater than hybrids variance components in all years and were significantly larger at $\alpha=0.10$ than hybrid variances in 1976, 1982, 1988, and 1992. The uniform nonsignificant response among hybrids and among purelines to the environmental index suggests no hybrid buffering across environments. This response was observed despite genetic differences in mean performance within each cultivar type. In addition, no differences were found between hybrids and purelines in their nonadditive response to the environmental index as indicated by the variance components for deviations being the same for both cultivar types.

\section{CONCLUSIONS}

An analysis of data for $21 \mathrm{yr}$ of hybrid and pureline grain yield in Oklahoma provides evidence of the continuing improvements made in grain yield for both. The genetic gain made in hybrids occurred at a greater rate than that of purelines. However, no differences in stability of grain yield were detected across different environments for either hybrids or purelines, and the average regression slopes of each were similar. Deviations of mean yield data from the stability regressions were of similar magnitude for hybrids and purelines, and confidence intervals for hybrid and pureline stability regressions generally overlapped. At its current rate of improvement in grain yield, hybrid wheat remains a tool to maximize wheat production; but from the data analyzed, 
there is not a stability advantage. Until the yield advantage is increased and seed costs reduced, hybrid wheat will not be commercially viable in the southern Great Plains of the USA.

\section{ACKNOWLEDGMENTS}

This research was supported by the Oklahoma Agricultural Experiment Station and the Oklahoma Wheat Research Foundation.

\section{REFERENCES}

Borojevic, S. 1986. World wheat production. p. 1-5. In E.L. Smith (ed.) Genetic improvement in yield of wheat. CSSA Spec. Publ. 13. ASA and CSSA, Madison, WI.

Bruns, R., and C.J. Peterson. 1998. Yield and stability factors associated with hybrid wheat. Euphytica 100:1-5.

Carver, B.F., E.L. Smith, and H.O. England. 1987. Regression and cluster analysis of environmental responses of hybrid and pureline winter wheat cultivars. Crop Sci. 27:659-664.

Clarke, F.R., R.J. Baker, and R.M. DePauw. 1994. Moving mean and least squares smoothing for analysis of grain yield data. Crop Sci. 34:1479-1483.

Cox, T.S., J.P. Shroyer, L. Ben-Hui, R.G. Sears, and T.J. Martin. 1988 Genetic improvement in agronomic traits of hard red winter wheat cultivars from 1919 to 1987. Crop Sci. 28:756-760.

Eberhart, S.A., and W.A. Russell. 1966. Stability parameters for comparing varieties. Crop Sci. 6:36-40.

Edwards, I.B. 2001. Hybrid wheat. p. 1019-1045. In A.P. Bonjean and W.J. Angus (ed.) The world wheat book: A history of wheat breeding. Lavoiser Publ., Paris.

Guenzi, A.C., R.G. Sears, and T.S. Cox. 1985. Stability analysis of winter wheat hybrids and cultivars. Annu. Wheat Newsl. 31:128.

Johnson, K.M., and K.A. Lucken. 1986. Characteristics and performance of male-sterile and hybrid seed produced by cross-pollination in hard red spring wheat. Crop Sci. 26:55-57.

Jordaan, J.P., S.A. Egelbreght, J.H. Malan, and H.A. Knobel. 1999. Wheat and heterosis. p. 411-421. In J.G. Coors and S. Pandey (ed.) The genetics and exploitation of heterosis in crops. ASA, CSSA, and SSSA, Madison, WI.

Khalil, I.H., B.F. Carver, E.G. Krenzer, C.T. MacKown, and G.W. Horn. 2002. Genetic trends in winter wheat yield and test weight under dual-purpose and grain-only management systems. Crop Sci. 42:710-715.

Payton, M.E., A.E. Miller, and W.R. Raun. 2000. Testing statistical hypotheses using standard error bars and confidence intervals. Commun. Soil Sci. Plant Anal. 31:547-551.

Peterson, C.J., J.M. Moffatt, and J.R. Erickson. 1997. Yield stability of hybrid vs. pureline hard winter wheats in regional performance trials. Crop Sci. 37:116-120.

SAS Institute. 1996. SAS user's guide: Statistics. SAS Inst., Cary, NC.

Schmidt, J.W. 1984. Genetic contributions to yield gains in wheat. p. 89-101. In W.R. Fehr (ed.) Genetic contributions to yield gains of five major crop plants. CSSA Spec. Publ. 7. ASA and CSSA, Madison, WI.

Schmidt, J.W., and W.D. Worrall. 1983. Trends in yield improvement through genetic gains. p. 691-700. In S. Sakamoto (ed.) Proc. 6th Int. Wheat Genet. Symp., Kyoto, Japan. 28 Nov.-3 Dec. 1983. Maruzen Co., Kyoto, Japan.

Yau, S.K., and J. Hamblin. 1994. Relative yield as a measure of entry performance in variable environments. Crop Sci. 34:813-817. 